\title{
Da culpa em Freud à responsabilidade em Lacan: paradigmas para uma articulação entre psicanálise e criminologia
}

From Freudian guilt to Lacanian responsibility: paradigms for an articulation between psychoanalysis and criminology

De la culpa en Freud a la responsabilidad en Lacan: paradigmas para una relación entre psicoanálisis y criminología

Fidias Gomes Siqueira*

\begin{abstract}
Resumo
Este artigo discute o paradigma da culpa em Freud e sua relação com o ato criminoso, propondo ainda uma articulação com o paradigma da responsabilidade em Lacan, apontando o possível diálogo entre psicanálise e criminologia no tratamento do sujeito criminoso.
\end{abstract}

Palavras-chave: Psicanálise. Criminologia. Culpa. Responsabilidade.

\begin{abstract}
This article discusses the Freudian paradigm of guilt and its relationship to the criminal act and also proposes an articulation with the Lacanian paradigm of responsibility, identifying the possible dialogue between psychoanalysis and criminology in the treatment of the criminal subject.
\end{abstract}

Keywords: Psychoanalysis. Criminology. Guilt. Responsibility.

\section{Resumen}

Este artículo analiza el paradigma de la culpa en Freud y su relación con el acto criminal, proponiendo una articulación con el paradigma de la responsabilidad en Lacan, señalando el posible diálogo entre el psicoanálisis y la criminología en el tratamiento del sujeto criminal.

Palabras clave: Psicoanálisis. Criminología. Culpa. Responsabilidad.

“Jamais pensei ter sido condenado sem razão” (Alexandre Soljenítsin, 1976)

Texto recebido em julho 2012 e aprovado para publicação em fevereiro de 2013.

*Mestrando em Teoria Psicanalítica pela FAFICH/UFMG, especialista em Segurança Pública e Justiça Criminal pela Fundação João Pinheiro, psicólogo, psicanalista. Endereço: Rua Turquesa, 311 - São Joaquim, Contagem-MG. CEP: 32113-050. E-mail: fidias.siqueira@gmail.com. 


\section{Introdução}

A contribuição da psicanálise ao estudo do homem em sua relação com o crime não é uma novidade. Este artigo procura situar as principais contribuições da teoria psicanalítica à criminologia, possibilitando avanços no tratamento do criminoso.

Partindo da concepção da culpa em Freud e da responsabilidade em Lacan é que se tomam estes dois paradigmas como principais orientadores na compreensão da relação do homem com o crime, bem como se apontam perspectivas às ciências humanas e criminais no tratamento do criminoso.

A relação do homem com o crime coloca questôes que não se encerram numa produção de respostas objetivas. Ao contrário, são as respostas particulares que interessam à psicanálise em sua articulação com a criminologia.

Trata-se menos de descrever ou caracterizar um perfil do criminoso, mas apresentar o paradigma da culpa como ponto de partida comum a todo homem, encontrando-se na sua origem a existência de alguma motivação que poderia ou não impulsionar o sujeito a cometer um crime. E, em seguida, discutir o paradigma da responsabilidade e sua importância na solução singular de cada sujeito; contribuindo, assim, para ampliar as perspectivas no campo de tratamento do criminoso.

\section{A culpa em Freud}

Se o crime não é algo novo, o caminho para compreender a relação do homem com o fenômeno remete à própria história da humanidade, sendo importante situar o que possibilita ao homem organizar a vida em sociedade, uma vez que essa organização parece não ocorrer de modo natural.

Em O mal-estar na civilização, Freud (1929/1974) afirma que a organização das relações entre os homens se dá com base nas exigências que a sociedade civilizada coloca como condiçôes para a vida humana. Tais exigências destacam um importante elemento: a agressividade humana.

Essa agressividade é demonstrável na relação do homem com o seu semelhante, na qual, muito mais que tomar o semelhante como o próximo a quem se pode amar, a tendência nessa relação é sempre de uma tentativa de dominação. Assim, Freud (1929/1974, p. 133) destaca que, entre os dotes pulsionais do homem, "deve-se levar em conta uma poderosa quota de agressividade". 
É importante considerarmos o papel da civilização na regulação das tendências agressivas do homem. O modo como isso ocorre é apontado pelo próprio Freud (1929/1974) como uma exigência de renúncia às suas satisfações imediatas. Essa condição já nos aponta uma interferência do mundo externo na regulação das forças internas no homem.

Se todos os homens têm uma inclinação agressiva, isso também produz efeitos nas relações com o semelhante. Freud (1929/1974) também destaca o papel da civilização no sentido de controlar tais tendências, já que sua liberação implicaria o fim da própria civilização. Por fim, ele ainda ressalta como são grandes os esforços da civilização para estabelecer limites às pulsões agressivas do homem e manter suas manifestações sob controle.

Desse modo, pode-se pensar que é incessante a luta da civilização para controlar as inclinaçôes agressivas do homem, bem como garantir a continuidade do processo civilizatório. Isso ocorre por meio de uma exigência da civilização ao homem para que renuncie às satisfações imediatas. E, como consequência, pagase um preço por tais renúncias.

Descoberto o modo como a civilização exerce controle sobre o homem e sabendo que isso não é gratuito, Freud (1929/1974) pergunta-se também se a civilização obtém êxito em seu intento. Ao que ele nos indica, apesar de todos os esforços, a civilização não conseguiu muito, pois "a lei não é capaz de deitar a mão sobre as manifestaçôes mais cautelosas e refinadas da agressividade humana" (Freud, 1929/1974, p. 134).

Devido ao fracasso da civilização em alcançar seu objetivo, Freud (1929/1974) destaca que a agressividade humana também se dirige contra a civilização e se interessa em saber como a civilização lida com essa agressividade que lhe é direcionada.

A resposta dada por Freud (1929/1974) é que essa agressividade é introjetada, internalizada, ou seja, essa agressividade exteriorizada retorna para o lugar de onde veio, ela retorna para o próprio eu. Assim, percorrendo o caminho para o interior, essa agressividade é assumida por uma parte do eu. E essa parte se coloca contra o resto do eu, sob a forma do "supereu". Essa instância coloca em ação contra o eu a mesma agressividade que este último teria dirigido aos outros indivíduos.

Anteriormente, Freud já havia destacado em O Ego e o Id (1923/1974) que quanto mais o homem controla a sua agressividade para com o exterior, mais severo (isto é, agressivo) ele se torna em seu ideal do eu. Quanto maior o controle dessa agressividade, mais intensa se torna a inclinação do ideal do eu contra o eu. Trata-se, portanto, de um retorno dessa mesma agressividade contra o seu próprio eu. 
Conforme isso ocorre, chama nossa atenção o nível de severidade presente na relação entre o eu e o supereu. Esse é um ponto importante em relação às consequiências desse retorno, pois, segundo Freud (1929/1974), o eu se encontra assujeitado ao supereu, que apresenta a sua face severa; resultando da relação entre o eu e o supereu uma tensão a que chamamos sentimento de culpa, seguida de uma necessidade de punição.

Segundo Freud (1929/1974, p. 146-147), a maneira como "a civilização consegue dominar o perigoso desejo de agressão do indivíduo é enfraquecendo-o, desarmando-o e estabelecendo no seu interior um agente para cuidar dele". Se o controle estabelecido pela civilização sobre a agressividade humana decorria da renúncia imposta à satisfação, levando à internalização da agressividade; agora a civilização conta com um agente interno que reforçará o controle, usando como arma o sentimento de culpa e a necessidade de punição.

Mas Freud (1929/1974) não se contentou com a solução encontrada pela civilização. Interessado em saber como uma pessoa vem a ter sentimento de culpa, ele parte da ideia de que uma pessoa se sente culpada quando fez algo que sabe ser mau. E dá um passo adiante ao afirmar que, mesmo quando a pessoa não fez algo mau, mas identificou em si uma intenção de fazê-la, tal pessoa pode se encarar como culpada. Assim ele também questiona como se dá o julgamento de uma ação como boa ou má, bem como o motivo que leva a igualar a intenção à ação de fazer algo mau.

Às voltas com a tentativa de responder suas indagações, Freud (1929/1974) nos fala que deveria haver uma condição de reconhecimento, ou seja, uma capacidade original de distinção entre bom e mau. Mas a sua constatação não segue esse caminho. Ele depara com a existência de uma influência estranha que opera nessa distinção, apontando para o motivo que leva a submeter-se a tal influência. Cabe perguntarmos qual é esse motivo.

Essa engenhosa construção remonta a uma situação ainda mais delicada. A descoberta de Freud (1929/1974) é que esse motivo pode ser encontrado no desamparo e na dependência da pessoa em relação às outras pessoas, e que isso pode ser mais bem designado como medo da perda de amor.

Inicialmente, podemos concluir que a origem do sentimento de culpa está relacionada com o desamparo humano e o medo da perda do amor. Isso revela a dependência humana e ressalta que o desamparo nos deixa à deriva, desprotegidos, suscetíveis aos perigos do mundo. Dentre esses perigos, Freud (1929/1974) ainda destaca o risco de essa mesma pessoa que protegia retornar sua autoridade sobre o indivíduo sob a forma de punição. 
Apesar da importante conclusão acima sobre a origem do sentimento de culpa, Freud (1929/1974) destaca que uma mudança ocorre quando a autoridade é internalizada pelo estabelecimento do supereu. Tudo pareceria resolvido em relação ao temor advindo do mundo externo, mas não seria bem assim. $\mathrm{O}$ supereu, essa nova autoridade, mesmo aparentemente sem motivos, ficaria à espreita, esperando os tropeços do eu para exercer seu domínio.

As elaborações até aqui apontam duas situações para a origem do sentimento de culpa. Freud (1929/1974) nos fala que a primeira situação decorre do medo da autoridade e do temor de perder o seu amor; e a segunda situação é aquela em que o sentimento de culpa surge do medo do supereu. E mais, ele diferencia, na primeira situação, a renúncia às satisfações pulsionais; enquanto, na segunda, à renúncia às satisfações acrescenta-se a exigência de punição, uma vez que os desejos proibidos não podem ser escondidos do supereu, motivo pelo qual ocorre o sentimento de culpa. Ao supereu vigilante e punitivo destacamos a severidade com que retorna contra o eu, já que substitui agora a autoridade externa.

Se a renúncia às satisfações pulsionais ocorria em relação ao temor a uma autoridade externa, agora essa autoridade se organiza internamente, e é por medo dela que essa mesma renúncia opera. É nesse caso que Freud (1929/1974) ressalta o momento em que as más intenções são igualadas às más ações, e daí surge o sentimento de culpa e a necessidade de punição.

Nesse sentido, a equivalência entre a intenção ou a prática de uma má ação demonstra que nada pode ser escondido do supereu, acrescentando-se à permanência do sentimento de culpa a necessidade de punição. Os desdobramentos decorrentes dessa associação serão importantes para entendermos a culpa como a via que impulsiona a busca pela punição.

Esse caminho já havia sido trilhado por Freud alguns anos antes e, em seu artigo de 1924, sobre O problema econômico do masoquismo (Freud, 1924/1974), ele delimitou a existência de três tipos de masoquismo: o erógeno, o feminino e o moral. Este último é o que Freud considera a forma mais importante assumida pelo masoquismo. É nesse tipo que a psicanálise identifica um sentimento de culpa que, na maior parte, é inconsciente e que encontra expressão no conteúdo manifesto das fantasias masoquistas. Segundo Freud (1924/1974), ao presumir o cometimento de algum crime, o indivíduo o expia por meio de procedimentos penosos e atormentadores.

Outro ponto destacado por Freud (1924/1974) é o fato de essa culpa que engendra tentativas de punição também encontrar sua raiz numa vinculação com a masturbação infantil. Assim, a culpa contribui para a transição à terceira forma de masoquismo: a moral. 
O que Freud (1924/1974) ainda destaca em relação ao masoquismo moral é a sua vinculação com a sexualidade afrouxada. Enquanto os dois tipos de masoquismo (o erógeno e o feminino) relacionam-se com a figura de uma pessoa amada e se estabelecem a partir de uma dependência em relação à pessoa que assume o papel de uma figura de autoridade; no caso do masoquismo moral, essa restrição em relação a uma figura de autoridade foi abandonada. O importante para o indivíduo é o sofrimento, independentemente de quem o decreta, de modo que tal sofrimento pode ser causado ou atribuído a "poderes impessoais, à força das circunstâncias" (Freud, 1924/1974, p. 206).

O perigo apontado por Freud (1924/1974) é o fato de esse masoquismo se originar da pulsão de morte e corresponder à parte da pulsão que escapou de ser voltada para fora como pulsão de destruição. Nesse sentido, podemos pensar que, se essa parte da pulsão não encontrou um meio de se exteriorizar, ela deve ter retornado contra o próprio eu. No entanto essa parte da pulsão de destruição tem um componente erótico, ou seja, uma possibilidade de extração de prazer. E, diante disso, Freud é categórico ao afirmar que até a destruição de si mesmo pelo próprio indivíduo não ocorre sem uma satisfação libidinal.

A partir da distinção das três formas de masoquismo, o enfoque no masoquismo moral muda sobremaneira a concepção acerca da necessidade de punição que advém do sentimento de culpa. O fato mais radical que se extrai é a constatação de que o indivíduo que renunciou às satisfações pulsionais internalizando a sua agressividade percorrerá um novo caminho até encontrar novamente outras vias de satisfação, mesmo que seja à custa de sua própria destruição.

Nesse sentido, a resposta encontrada por Freud (1929/1974) para se entender como a civilização domina as tendências agressivas do homem é o sentimento de culpa. É o que possibilita a organização dos homens entre si à custa da renúncia às satisfaçôes mais imediatas e intensas. Mas esse objetivo somente será alcançado pelo fortalecimento do sentimento de culpa. Entretanto isso não será sem consequências para a própria civilização, e o que Freud (1929/1974) ressalta é que "essa culpa pode não ser percebida como tal, em grande parte pode permanecer inconsciente, ou pode aparecer como uma espécie de mal-estar, uma insatisfação, para a qual as pessoas buscam outras motivações" (p. 160).

No cerne dessas motivaçôes, sob o nome de mal-estar, encontramos a culpa colocando em curso a ação criminosa. Freud (1916/1974) descobre a relação da culpa com algumas ações proibidas a partir de observações estabelecidas em seu artigo Criminosos em conseqüência de um sentimento de culpa, no qual seus pacientes relatam a prática de atos criminosos como furtos, fraudes ou incêndio voluntário, e que, se num primeiro momento, não tinham importância, chamam 
a sua atenção quando essas situações ocorrem em pacientes que já não são tão jovens e estão sob seus cuidados.

A descoberta de Freud (1916/1974) aponta um fato interessante, pois tais atos eram praticados por serem proibidos, e sua execução acarretava um alívio. A investigação aponta que a pessoa já sofria um opressivo sentimento de culpa, mas não conhecia sua origem. Ao praticar uma ação má, essa opressão se atenuava. Isso decorria do fato de que agora havia um motivo que justificasse o sentimento de culpa.

O sentimento de culpa estava presente antes da ação, e o ato criminoso decorreu do sentimento de culpa e não como consequência da ação. Essas pessoas foram descritas como "criminosos em consequência de um sentimento de culpa". Mas é importante considerar que nem todas as pessoas cometiam atos criminosos em decorrência desse sentimento de culpa. Havia também aqueles indivíduos que praticavam o ato criminoso e não sentiam culpa. Como também é importante destacar que nem todas as pessoas, por terem um sentimento de culpa, cometerão um ato criminoso.

Apesar de localizar o papel da culpa no crime humano, Freud pouco se dedicou a apontar um possível tratamento para o criminoso. Poucas vezes retomou essa discussão na perspectiva da criminologia. Entretanto sua invenção, até hoje, coloca-nos a trabalho ao percorrermos o engenhoso percurso construído para localizar a culpa no cerne da existência humana e no advento da civilização.

\section{A responsabilidade em Lacan}

É em torno da dimensão da responsabilidade como paradigma no tratamento do criminoso que se parte do ensinamento de Lacan, sendo necessário, porém, situar o que ele pensava e como construiu seu diálogo com a criminologia de sua época.

Para compreender o diálogo de Lacan com a criminologia de sua época, partimos da discussão que ele faz em $1950 \mathrm{em}$ Introdução teórica às funções da psicanálise em criminologia (1950/1998, p. 128). Ele destaca que, se a teoria nas ciências físicas exige uma coerência interna que leva à produção do conhecimento, em relação às ciências do homem, ele ressalta que a resposta não se impóe em termos de verdade. Ressalta ainda que a busca da verdade constitui objeto da criminologia e tem duas faces: a verdade do crime em sua face policial, e a verdade do criminoso em sua face antropológica. 
Nesse sentido, a discussão suscitada por Lacan (1950/1998) não está reduzida a tratar da contribuição da psicanálise ao estudo da delinquência, mas propor o estabelecimento dos limites legítimos da psicanálise em criminologia. Essa diferenciação é crucial para que a psicanálise possa definir sua ação e seu alcance, sem entrar na perspectiva da investigação tal como se propõe a criminologia.

Para Lacan, a concepção do crime e do criminoso não pode ser pensada fora de sua referência sociológica. Assim, torna-se necessário entender a relação que cada sociedade estabelece com a concepção de crime e de criminoso numa determinada época. Dessa maneira, Lacan (1950/1998) ressalta a existência, em cada sociedade, de uma lei positiva, tradicional ou escrita, de costume ou de direito, assim como os graus de transgressão que definem o crime.

Se a lei e o grau de transgressão definem o crime numa dada sociedade, deve-se também perguntar como essa mesma sociedade responde em relação à aplicação dessa lei sobre o transgressor. Lacan (1950/1998) afirma que "toda sociedade manifesta a relação do crime com a lei através de castigos cuja realização, sejam quais forem suas modalidades, exigem um assentimento subjetivo" (p. 128).

Se a relação do crime com a lei se dá pelo castigo, a sua aplicação também traz a dimensão do assentimento subjetivo. Esse é necessário para dar significação à punição. Mas precisamos destacar que o assentimento subjetivo não é apenas a concordância do indivíduo com o castigo. É necessário mais do que isso. É necessário que o sujeito surja diante daquilo que o causa.

Assim, se até aqui Lacan (1950/1998) faz referência à relação das sociedades primitivas com o crime e a punição, ele também ressalta que, em nossa sociedade, essa relação com a punição se dá pelo termo responsabilidade. É nesse ponto que se destaca o modo como a psicanálise pode contribuir com a criminologia, a saber, com a noção de responsabilidade.

Tal noção não se restringe apenas a assumir o ato que lhe é imputado. A responsabilidade implica uma relação com a causa do seu ato, ou seja, qual ponto da subjetividade foi tocado e produziu esse ato como resposta. E é diante disso que se deve responder, pois da posição de sujeito somos sempre responsáveis.

Lacan (1950/1998) também faz referência àquilo que repercute no indivíduo e se encontra descrito como culpa. Para ele, a culpa é a revolução na descoberta freudiana, ao se destacar como uma categoria onipresente desde então.

Dessa maneira, ao percorrer a descoberta freudiana onde a relação da culpa com o supereu estava alinhavada, Lacan $(1950 / 1998)$ faz avançar as contribuições da psicanálise à criminologia a partir dos crimes determinados pelo supereu. Ele apresenta uma nova concepção da determinação para o crime, avançando a descoberta freudiana. 
Em seu diálogo com a criminologia da época em articulação com a psicanálise, Lacan (1950/1998) afirma que "a psicanálise soluciona um dilema da teoria criminológica: ao irrealizar o crime, ela não desumaniza o criminoso” (p. 137).

É necessário entender tal afirmativa e o que ela coloca como cerne do tratamento do criminoso. Em primeiro lugar, Lacan (1950/1998) formula uma orientação psicanalítica para o tratamento do criminoso que se opõe à proposição criminológica, produzindo-se uma modificação na compreensão da relação entre o criminoso e o crime.

Em segundo lugar, devemos extrair da proposição lacaniana a consideração do aspecto subjetivo em que a motivação do crime encontra sua vinculação com os fatores inconscientes. E se há uma relação entre o fato criminoso e aspectos inconscientes, deve-se também levar em consideração como as instâncias psíquicas atuam articuladas em determinados tipos de crime e, atentos a essa articulação, podemos compreender como os resquícios decorrentes da experiência edípica serão determinantes numa busca de punição que provocaria alívio no sujeito devido aos seus desejos incestuosos e parricidas.

E em terceiro lugar, deve-se entender que tal afirmação proposta por Lacan não isenta o criminoso, não o desresponsabiliza. Ao contrário, é por considerar a articulação dos aspectos inconscientes que a psicanálise possibilita que o criminoso não perca sua dimensão humana. Considerando tais aspectos da trama simbólica e inconsciente, ela convoca o sujeito a falar e a responder por seu ato, garantindo assim sua permanência na comunidade humana.

E para elucidar a proposição lacaniana, Santos (2013) afirma:

Lacan busca assinalar que o psicanalista não vai levar em consideração o crime em si, mas as engrenagens psíquicas que o engendram, buscando tocar nos elementos que compõem o simbolismo individual que por ele é escamoteado. Lacan, portanto, pretende colocar em evidência a necessidade de se aproximar da manifestação criminosa (ou psicopática) de um modo cauteloso, buscando enxergar nela aquilo que há de mais particular no sujeito que a executa em sua relação com a trama social e simbólica que lhe é correspondente (p. 92).

É por isso que não devemos buscar a verdade do criminoso na realidade dos fatos, mas na realidade psíquica, pois é nesta que localizamos os aspectos simbólicos e inconscientes que se articulam à experiência subjetiva, e somente assim podemos compreender a relação entre o criminoso e seu crime. Do contrário, poderemos incorrer no aspecto da investigação policial ou na consideração do senso comum que toma o crime pelo seu aspecto absurdo e sem sentido. 
Em Premissas a todo desenvolvimento possivel da criminologia, Lacan (1950/2003) também localiza um problema em relação a essa afirmação. Ao destacar as contribuiçôes da psicanálise ao desenvolvimento da criminologia, ele aponta para aonde tende a criminologia e, se ela chega a humanizar o tratamento do criminoso, somente o faz ao preço de um declínio de sua humanidade. Tal afirmação realça o ponto em que a criminologia se distancia da perspectiva psicanalítica.

Mesmo ao humanizar o tratamento do criminoso, se a criminologia o encerra na dimensão da loucura, tira-lhe a possibilidade de responder por seu ato como qualquer outro ser humano. Diferente disso, a aposta da psicanálise é que todo sujeito possa responder por seu ato, seja sua posição subjetiva articulada à psicose, à neurose ou à perversão; seja o criminoso um adulto ou um jovem.

Nesse sentido, Lacan (1950/2003) destaca que a contribuição da psicanálise no campo de um tratamento possível do criminoso deve considerar o crime compreendido dentro de uma estrutura fechada da subjetividade, destacando a estrutura do supereu também na sua relação com a consciência moral e com a ambiguidade do sentimento de culpa.

O que podemos extrair da afirmação de Lacan é que o crime não pode ser pensado como um evento isolado, mas deve ser considerado numa articulação da subjetividade; não perdendo de vista a relação entre o supereu e o sentimento de culpa.

Deve-se levar em consideração que é pela ambígua relação com o sentimento de culpa e também com o supereu que se pode entender como o sujeito busca por si mesmo uma maneira de encontrar na punição um apaziguamento para sua culpa.

Lacan (1950/2003) nos fala que o campo de tratamento do criminoso tende para a integração pelo sujeito de sua verdadeira responsabilidade, fato que ele tendia por vias confusas, buscando ele mesmo uma punição. Dessa maneira, o sujeito pode responder pelo seu ato, e essa possibilidade lhe garante uma retificação em sua posição.

Ao falarmos de uma retificação subjetiva, somente podemos compreendê-la através da noção de responsabilidade. Para que isso ocorra, Lacan (1950/2003) destaca ainda o papel que cabe à psicanálise de libertar a verdade do ato, comprometendo com ele a responsabilidade do criminoso, por meio de uma assunção lógica que deverá conduzi-lo à aceitação de um justo castigo. 
É a ideia de responsabilidade que se encontra no cerne da proposição psicanalítica para o tratamento possível do criminoso. Tal noção é o que possibilita a não exclusão do criminoso da sua condição de sujeito. E também não o isenta de responder por seu ato.

Finalmente, Lacan (1950/2003) fala dos limites da psicanálise no tratamento do criminoso, advertindo-nos que é no campo da ação policial que a psicanálise deve se recusar a entrar. Se a ação da psicanálise se sustenta sobre a noção de responsabilidade, ela só o faz porque a sua aposta é não tirar do criminoso a sua própria humanidade e, ao contrário, promover a emergência do sujeito e sua inclusão na comunidade humana.

\section{Esse "obscuro sentimento de culpa": Relato de uma história ${ }^{1}$}

Zinho tinha 40 anos quando o encontrei pela primeira vez em janeiro de 2003. Estava preso há quatro anos. Havia sido condenado a uma pena de 15 anos como mentor de um latrocínio. Já de início, me falou da imposição institucional sobre o tratamento psicológico e me indagava sobre o que eu queria saber dele. Sobre sua vida, disse que é uma longa história e estava pagando por um crime que não cometeu.

Era comerciante, trabalhador. Certo dia, vira dois rapazes fugindo da polícia, depois soubera que eles foram presos acusados de homicídio. O tempo passou, e ele se esquecera da história; até que um dia apareceram policiais em seu bar e o intimaram a acompanhá-los à delegacia.

Eles me levaram às dez horas da manhã, me espancaram até às dez horas da noite. Não falavam o que era, nem por quê. Até que eu fiquei em pé, e um deles me empurrou e falou que eu tinha mandado matar o cara. Eu não conhecia esse cara que foi morto, nunca tinha visto. Fiquei preso e fui condenado a quinze anos de prisão por um crime que não cometi.

Para justificar a acusação, falaram que ele mandou matar porque a vítima tivera um caso com sua mulher; em seguida, falaram que era para comprar o carro roubado. Não encontrava motivação para o roubo sendo trabalhador. Mas os rapazes que o acusaram foram soltos, e ele permaneceu preso. Perdeu seu patrimônio para pagar honorários advocatícios, e sua família passava dificuldades. Ele foi preso por algo que não fizera. Na época do julgamento, falou para o juiz: "Doutor, o senhor está me condenando por uma coisa que não fiz".

1 Atendimentos realizados durante estágio extracurricular em Psicologia, vinculado à PUC Minas e supervisionado pela professora Lúcia Efigênia Gonçalves Nunes, ocorrido na APAC (Associação de Proteção e Amparo ao Condenado) de Sete Lagoas-MG. 
Durante os atendimentos, perguntava-me o que eu queria saber dele. Disselhe que me falasse de sua história, sem entrar na perspectiva investigativa. Sua vida sempre foi muito dura e triste. Sofreu muito e se esforçava para tirar a mãe da miséria. Trabalhava para oferecer a ela melhores condições. Seu irmão mais velho não trabalhava e, certa vez, acusou-o de ter comido o peixe do almoço, motivo pelo qual sua mãe lhe deu uma surra.

Definiu-se como um homem sozinho. Sendo essa sua principal característica, gostava de estar sozinho, apreciar a natureza e conversar com as árvores, mas achava que não era doido, apenas "pensava demais". A partir desse encontro, ele havia se perguntado o motivo de sempre ter assumido a culpa por coisas que não fez. Ressaltei o fato de ser acusado por um crime que não cometeu.

Chegou ao atendimento seguinte se perguntando: "Por que estou pagando por um crime que não cometi?”. Lembrou-se da história do irmão que comeu o peixe e o acusou. Certa vez, deu uma facada no irmão, brigou com um colega de trabalho, perdeu o dinheiro do patrão, traiu a mulher. Pensa que somente podia estar pagando por essas coisas que fez.

Um dia, falou da vergonha que sentia e se achava diferente. Achava que seu problema era a vergonha. Sentia vergonha em relação a um tipo de gente: as autoridades, o que não ocorria em relação à "gente simples". Mesmo tendo vergonha das pessoas, ressaltava sua facilidade em conquistar as mulheres, mas enquanto não se acostumava com elas, somente transava no escuro. $\mathrm{Na}$ adolescência, saiu correndo de uma consulta quando o médico o mandou tirar a roupa e lhe passou a mão. Em seguida, começou a rir e se lembrou da cena em que a mãe o encontrara se masturbando aos 8 anos de idade. Ela ameaçou bater, ele sentiu-se muito envergonhado e nunca esqueceu essa cena. A isso associava a origem da sua vergonha.

Disse que sempre foi triste e não sabia o porquê. Tinha uma angústia dentro de si. Tinha sonhos angustiantes e acordava apavorado. Mesmo pensando que os sonhos eram sem sentido, temia sonhar por acreditar que algo aconteceria depois. Recorria à leitura da Bíblia, pensava nos erros do ser humano e concluía: "O homem, sendo pecador desde o início de sua existência, não tem como ser diferente".

Estava cansado de pagar por um crime que não cometera e me disse: "Eu achava que essas coisas só aconteciam em novelas". Recordando-se da história do peixe, considerava que a verdade levou 40 anos para ser dita. Não entendia por que pagava pelas ações dos outros. Não sabia se isso é espiritual ou da vida, já que o sofrimento sempre o acompanhava. 
Esperava construir provas para se inocentar. Acreditava na possibilidade de influenciar os homens que o acusaram de participar do crime a dizer a verdade. Achava possível induzir as pessoas a contarem aquilo que se queria ouvir delas, e falava isso se referindo também à prerrogativa de minha formação profissional.

Em relação a essas provas, recordava-se da situação em que o vizinho avisara para que fosse à escola do seu filho, pois um colega do menino havia dado $\mathrm{R} \$$ 5,00 para dois caras matarem seu filho. "Eu os ameacei, e disse que ia chamar a polícia, acho que foi aí que fui envolvido."

Em outro atendimento, dizia que não estava entendendo-se, achava que algo estranho estava acontecendo com ele. Estava brigando com as pessoas, com raiva, não entendia por que estava reagindo assim. Queria sair da prisão e reafirmava não ter cometido o crime pelo qual estava preso. Perguntei-lhe "pelo que" estava pagando e encerrei. Ele ainda me disse que falava a verdade, "porque, se eu falar uma mentira, não tenho sossego na consciência”.

Diante do anseio pela liberdade, relatava sua disposição para pagar aos acusadores, a fim de que dissessem a verdade. Novamente perguntei pelo que estava pagando, encerrando o atendimento e apostando nos possíveis efeitos que essa pergunta pudesse produzir.

Em outro encontro, relatava um susto que levou com o sumiço de um objeto de um dos presos. Quando repito "susto...", ele disse que vivia levando sustos. $\mathrm{Na}$ infância, assustara-se com uma coruja, tivera muito medo. Certa vez, tivera alguma doença, e a pele de seu corpo se arrancara toda. Em outra ocasião, perdera a voz e fizeram simpatia com uma "maritaca" para que voltasse a falar. Diante de meu riso, ele se lembrou de outro susto: quando fora ao cinema pela primeira vez e vira uma aranha no filme, chegou em casa chorando e não conseguiu dormir. E, mais uma vez, se recordou do susto quando a mãe o vira se masturbando.

No penúltimo encontro, quando finalizava meu estágio na instituição, ele relatou um fato novo que poderia ser esclarecedor no processo judicial. Apareceram novas testemunhas, descobria-se a existência de outro Zinho, tinha ocorrido uma confusão de nomes. Digo-lhe: "Então apareceu um outro Zinho". Ele me disse não entender por que aconteceu isso com ele. No último encontro, relatando mais uma vez sua esperança de ser inocentado, ele disse que estava sendo testado, como sempre foi na sua vida, e se perguntou: "O que eu estou fazendo aqui, gente?".

Disse-me da esperança em provar sua inocência, sair da prisão e me encontrar; provando, assim, que estava pagando por um crime que não cometera. Em 2012, um amigo que participou do estágio na mesma instituição comigo, com quem já 
havia discutido o caso, relatou-me ter encontrado esse homem trabalhando num restaurante da cidade. Nesse período de quase dois anos, assisti o testemunho dos obscenos caminhos trilhados pela culpa; da sua "inocência" ainda não tive notícias...

\section{Considerações finais}

Se Freud faz uma revolução ao descobrir o "obscuro sentimento de culpa", Lacan faz avançar a articulação entre psicanálise e criminologia por considerar a importância da relação entre a culpa e a responsabilização no tratamento do criminoso.

O que se pretendeu neste artigo foi demonstrar a que caminhos a culpa pode conduzir o homem. Distante da prerrogativa de investigação policial pode o psicanalista apresentar ao sujeito uma possível responsabilização frente ao seu destino.

O relato dessa história também nos deixa uma interrogação sob o ponto de vista ético. Se a realidade factual traz o ponto cego da justiça, a realidade psíquica revela a dimensão de verdade que a culpa impõe ao destino humano.

Os pontos capitais nessa história se relacionam com a assunção pelo sujeito de uma culpa mais-além da realidade dos fatos. Sua intrincada relação com a culpa encontra-se construída numa anterioridade do fato que culminou com a acusação e prisão.

Os encontros com esse homem possibilitaram que, da formulação de sua sentença (pagar por um crime que não cometeu), ele pudesse transformá-la numa pergunta. E as recordações da sua história possibilitaram recompor a construção da culpa em sua vida.

Sua fala perante o juiz acerca da condenação por algo que não fez também possibilita pensar no efeito dessa condenação sobre seus outros atos. A acusação do irmão, cuja verdade levou 40 anos para aparecer, surge como primeira recordação que possibilita formular a pergunta sobre o motivo de sempre ter assumido a culpa por coisas que não fez. Mas é interessante porque, ainda neste tempo, atribui a outros atos (brigas, perda do dinheiro do patrão e traição à mulher) a causa do seu infortúnio.

O ponto crucial é a cena da masturbação, que, sob o sentimento de vergonha, encobrirá a culpa. Mais interessante ainda constatar a relação dessa vergonha com as pessoas que remetem à figura de autoridade, demonstrando assim a força do vigilante agente interno e a sua poderosa arma: a culpa. 
De um susto sofrido na atualidade (sumiço de um objeto de outro preso) recorda os sustos levados na infância no encontro com a coruja, com a doença, com a perda da voz, com a aranha na tela do cinema, e, enfim, com aquilo que se encontra na constituição da sexualidade (a masturbação infantil). Assim, é a partir desse ponto que sucessivamente o sujeito colhe em sua história os inúmeros efeitos da culpa e da necessidade de punição.

Gerez-Ambertín (2009) destaca a culpa como o fio de Ariadne que conduz da "instância crítica" até os crimes capitais (incesto e parricídio) e desses aos tipos de caráter. E em relação aos três tipos de caráter, a autora destaca o terceiro tipo (Criminosos em consequência de um sentimento de culpa) como aquele a partir do qual Freud avança na construção da teoria da culpa e da "instância" ligada à consciência moral.

ParaGerez-Ambertín(2009), "Aculpanãoprovocasomenteautoaniquilamento, ela também promove o crime com o fim de obter, com o seu castigo, o apaziguamento que precisa" (p. 82). No caso apresentado, pode-se pensar que os elementos destacados em sua relação com a culpa devem ter contribuído para que o sujeito buscasse um apaziguamento daquilo que ele mesmo nomeou como uma tristeza cujo motivo era desconhecido, uma "angústia" sentida dentro de si. Algo que pode ter levado a encontrar nessa condenação algum tipo de alívio.

Ainda é preciso destacar o que Gerez-Ambertín (2009) fala sobre a bifurcação dos caminhos paradoxais da culpa em relação ao criminoso, já que "não é a mesma culpa a que promove o crime e a que é sancionada com o castigo" (p. 82). Assim, torna-se importante distinguir a incidência da culpa que impulsiona o cometimento do ato criminoso, propiciando um alívio, daquela culpa que visa à obtenção da punição. Pode-se pensar que esse tenha sido o caminho pelo qual o sujeito se enveredou tentando apaziguar a culpa num crime que não cometeu.

É interessante notar, nesse caso, que, independentemente da realidade de fato, ou seja, de ele ter alguma relação com esse crime, não se pode desconsiderar a culpa anterior ao crime de que foi acusado. Essa condenação localizou a culpa em sua dimensão subjetiva, fato que escapou às ciências da criminologia e à própria justiça.

Por isso se deve concordar com Gerez-Ambertín (2009):

Se o que insta a cometer um crime é na realidade uma alegação para obter, com o castigo, um alívio para a culpa, é porque a verdade desta está em outra parte que sempre fica impune. Além da satisfação, o castigo produz uma razão válida para aliviar a secreta falta. Portanto, ele convida a "seguir pecando" (p. 83). 
A partir dessa afirmativa, ao considerar a verdade em sua dimensão subjetiva, consegue-se também entender onde a psicanálise se diferencia da criminologia. Para a psicanálise, a verdade se encontra na dimensão da realidade psíquica, enquanto, para a criminologia, está na realidade dos fatos. Assim, não nos cabe entrar no âmbito da ação policial ou investigativa, afinal, dada a condição estrutural da culpa, cabe a cada um a sua responsabilidade. Mas a condição da culpa também não nos exime de responder juridicamente por nossos atos.

Se a verdade surge na dimensão do equívoco, no caso apresentado, parece que a ficção ganhou contorno de realidade. Se o personagem dessa história estava às voltas com a obscuridade da culpa, pensando que essas coisas somente aconteciam em novelas, tornou-se o protagonista principal do intrincado enredo de sua novela da vida real.

\section{Referências}

Freud, S. (1974). Alguns tipos de caráter encontrados no trabalho psicanalítico: criminosos em consequência de um sentimento de culpa (J. Salomão, Trad.). In S. Freud, Edição standard brasileira das obras psicológicas completas de Sigmund Freud (Vol. 14, pp. 375-377). Rio de Janeiro: Imago. (Trabalho original publicado em 1916)

Freud, S. (1974). O Ego e o Id (J. Salomão, Trad.). In S. Freud, Edição standard brasileira das obras psicológicas completas de Sigmund Freud (Vol. 19, pp. 13-83). Rio de Janeiro: Imago. (Trabalho original publicado em 1923)

Freud, S. (1974). O mal-estar na civilização (J. Salomão, Trad.). In S. Freud, Edição standard brasileira das obras psicológicas completas de Sigmund Freud (Vol. 21, pp. 75-171). Rio de Janeiro: Imago.(Trabalho original publicado em $1930(1929))$

Freud, S. (1974). O problema econômico do masoquismo (J. Salomão, Trad.). In S. Freud, Edição standard brasileira das obras psicológicas completas de Sigmund Freud (Vol. 19, pp. 197-212). Rio de Janeiro: Imago. (Trabalho original publicado em 1924)

Gerez-Ambertín, M. (2009). As vozes do supereu: na clínica psicanalítica e no malestar na civilização. Rio de Janeiro: Companhia de Freud.

Lacan, J. (1998). Introdução teórica às funções da psicanálise em criminologia (V. Ribeiro, Trad.). In J. Lacan, Escritos (pp. 125-151). Rio de Janeiro: Jorge Zahar.(Trabalho original publicado em 1950) 
Lacan, J. (2003). Premissas a todo desenvolvimento possível da criminologia (V. Ribeiro, Trad.). In J. Lacan, Outros escritos (pp. 127-131). Rio de Janeiro: Jorge Zahar. (Trabalho original publicado em 1950)

Santos, M. J. M. (2013). Sob o véu da psicopatia (Dissertação de mestrado). Universidade Federal de Minas Gerais, Programa de Pós-Graduação em Psicologia, Belo Horizonte.

Soljenítsin, A. (1976). O Arquipélago Gulag. Rio de Janeiro: Biblioteca do Exército. 